\title{
Mindfulness and self-efficacy in pain perception, stress and academic performance. The influence of mindfulness on cognitive processes
}

This article was published in the following Dove Press journal: Psychology Research and Behavior Management

\author{
Andrea Margaret Firth ${ }^{1, *}$ \\ Ingvild Cavallini ${ }^{2} *$ \\ Stefan Sütterlin ${ }^{3}$ \\ Ricardo G Lugo 4 \\ 'Department of Psychology, University \\ Campus Football Business, London, UK; \\ ${ }^{2}$ Aarhus University, Copenhagen, \\ Denmark; ${ }^{3}$ Faculty of Health and Welfare, \\ Østfold University College, Norway and \\ Division of Clinical Neuroscience, Oslo \\ University Hospital, Norway; ${ }^{4}$ Inland \\ Norway University of Applied Science, \\ Lillehammer, Elverum, Norway
}

*These authors contributed equally to this work
Correspondence: Ricardo G Lugo Inland Norway University of Applied Sciences, PO Box 400, 2418 Elverum, Norway

Tel +47 61288156

Email Ricardo.lugo@inn.no
Purpose: This study seeks to understand the mediating effects of mindfulness on selfefficacy, academic performance and ability to cope with pain. It further examines the effect of mindfulness on the capacity to cope with pain-induced stress. Whilst there are physiological changes which occur due to mindfulness, it is still not clearly understood how the mechanisms behind mindfulness work or whether the role of self-efficacy is an agent of mindfulness which may impact on performance and stress coping.

Participants and methods: A three-part study ( $n=92)$ was conducted to test the relationship between mindfulness, self-efficacy and well-being factors, alongside academic performance in university students. Part one involved data collection one month prior to an experiment where trait scores for all factors were used to check pain and well-being behaviors. Part two consisted of participant randomization into three intervention groups (control, sham, mindfulness) and then an exposure to a fear induction task followed by cognitive tasks. The third part consisted of investigating the effect of a short mindfulness intervention on self-efficacy, pain and well-being in students.

Results: The results indicate that self-efficacy had a positive effect on well-being factors (study $1 \& 3$ ) and in the experiment (study 2).

Conclusion: Self-efficacy influenced pain intensity and pain unpleasantness and significantly predicted academic performance. Mindfulness had mixed results in how it influenced self-efficacy. While it influenced well-being and lowered stress (study $1 \& 2$ ) in the long term, the mindfulness intervention significantly decreased self-efficacy.

Keywords: self-efficacy, stress, mindfulness, short-term intervention

\section{Introduction}

Pain has been defined by the International Association for the Study of Pain ${ }^{1}$ as an unpleasant sensory and emotional experience associated with actual or potential tissue damage, or described in terms of such damage. Pain can divert attention from other stimuli onto the pain-focused situation which then requires further action. ${ }^{2}$ Such action is based on the level of current pain and the intensity of pain perception. Studies have indicated that pain perception and ability to function with pain can be influenced by perceived self-efficacy. ${ }^{3,4}$

Self-efficacy plays a major part in daily functioning, affecting decision making, behavior and cognition. Stemming from social cognitive theory, ${ }^{5,6}$ self-efficacy concerns the ability to self-regulate and control personal destiny. ${ }^{7,8}$ It is generally thought to be specific in that it concerns personal evaluation of the ability to complete 
a specific task. ${ }^{9,10}$ However, it need not be restrained to specific situations and in terms of general self-efficacy can be broadly applied. This type of self-efficacy is central to coping ability and wide-scale functioning as it is directly linked to coping skills. ${ }^{11}$ Self-efficacy is a mediating factor in a number of coping mechanisms and positive behavioral health responses both psychologically ${ }^{12}$ and physically, including the ability to cope with pain., ${ }^{43}$ Self-efficacy has also been found to be a mediating factor in self-regulation skills such as mindfulness skills ${ }^{14}$ which in turn is correlated with satisfaction with life. ${ }^{15}$

General self-efficacy can predict effort, perseverance and success in more than one unrelated task ${ }^{16}$ and the ability to cope well in stressful circumstances. ${ }^{17}$ Furthermore, generalized self-efficacy is versatile with high levels of general self-efficacy incorporating the ability to self-motivate, control emotional states, problem solve and apply positivity and optimism in the accomplishment of relevant tasks. ${ }^{18}$ General self-efficacy also helps coping skills along with persistence and effort in motivating conduct toward goals and belief in the ability to reach these goals. ${ }^{9}$

A large amount of research is dedicated to finding different ways to reduce stress and pain and both mindfulness-based and self-efficacy-based interventions have had beneficial effects. Mindfulness is a broad concept that can be conceptualized as the ability to regulate attention, whilst not attending to any detailed focus on present experience, yet remaining accepting, open and curious of this experience. ${ }^{19}$ Mindfulness requires attentional resources while maintaining a non-judgmental awareness of the present moment. ${ }^{20}$ The Mindfulness-Based Stress Reduction (MBSR) program was developed to reduce pain and stress using different mindfulness techniques. ${ }^{21}$ These were based on studies using healthy populations and when compared to a non-treatment condition, showed a significant reduction in general stress after completion of the stress reduction intervention. ${ }^{22}$

\section{Self-efficacy, breathing-based mindfulness and pain-related behavior}

Bandura's social cognitive theory argues that via self-regulation individuals have the ability to control their actions. ${ }^{8}$ Self-efficacy can increase self-regulated behavior through motivation, where past mastery performance reinforces the expectation of future success leading to increased learning and positive behavior. It increases individual expectation of future success in similar situations based on successful past mastery experience. In other words, personal belief in the ability to perform the action required and in self-regulated behavior is increased. ${ }^{23}$

Social cognitive theory purports that self-regulated behavior is fundamental to human action. ${ }^{5}$ Both physical and mental control are areas in which self-regulation has demonstrated positive effect in pain management. The ability to control one's situation, to lower anxiety and conditioned fear is psychologically beneficial, resulting in reduced perceptions of pain. ${ }^{24}$ Due to the debilitating nature of pain and the accompanying stress, enhancing coping mechanisms deserves further investigation.

In chronic pain patients, self-efficacy predicts avoidant behaviors and having mediating effects on pain intensity that may lead to disability. ${ }^{25-27}$ Low self-efficacy also influenced the expectation of pain. People with higher levels of self-efficacy cope better with stress and selfefficacy mediates stress-related depression and perception of pain in university students. ${ }^{28}$ It also moderates negative affect. $^{29,30}$

Recent studies on mindfulness have highlighted that mindfulness practice has a broad range of benefits including, increasing working-memory, psychological functioning and decreasing depressive symptoms including negative affect and rumination. ${ }^{20}$ MBSR significantly reduces both PostTraumatic Stress Disorder (PTSD) and depressive symptoms in abuse victims by increasing self-efficacy. ${ }^{31}$ For instance, an eight-week mindfulness intervention reduced stress whilst increasing self-efficacy and motivation in unemployed job seekers. ${ }^{32}$ Similarly, mindfulness appeared to increase selfefficacy in stress perception in college students. ${ }^{33}$ Mindfulness-based interventions have improved efficacy in preventing depression in pregnant women. ${ }^{34}$

The relationship between self-esteem, mindfulness ability and satisfaction with life directly impacts on coping mechanisms and behavioral functioning. The mediating relationship of general self-efficacy on these constructs is worth further investigation as potential interventions that increase general self-efficacy could mediate optimum psychological and physical functioning.

Previous research on both mindfulness and self-efficacy suggests they have an important role in both coping with stress, pain, and the promotion of positive affect, increased satisfaction with life and self-esteem. ${ }^{22,35}$ The ability to function at an optimal level, cope with stress and minimize the effects of perceived pain has economic, personal as well as social implications. Mindfulness is associated with self-efficacy and self-efficacy improves 
the ability to cope better with pain. ${ }^{36}$ Likewise, self-efficacy is also related to academic. ${ }^{37-40}$ However, the effectiveness of mindfulness in improving self-efficacy is not fully established. Cautiousness around mindfulness interventions should also be taken. Mindfulness-based interventions had detrimental effects in several patient groups. ${ }^{41}$ Mindfulness practices based on focused attention, but not body awareness, have also elicited unwanted effects in mindfulness practitioners. ${ }^{42}$ Other negative effects include meditation practitioners suffering from severe and long-lasting distress ${ }^{43}$ and even skilled mindfulness practitioners can experience negative consequences. $^{42,43}$

Mindfulness-based interventions have been shown to have positive effects on student populations. Such interventions are now included in medical training to prevent future burn-out. ${ }^{44}$ Such interventions were effective in training nurses in moral decision making whilst improving quality of life reports. ${ }^{45}$ Mindfulness-based interventions also improved memory and attentional processed in health science students. ${ }^{46}$

Short duration mindfulness intervention (1-time, 5-15 mins duration) can improve cognitive control and performance, ${ }^{47}$ decrease stress ${ }^{48}$ and inhibit craving for. ${ }^{49}$ Mindfulness-based interventions have good effects even between similar conditions vs control. For example, between a mindfulness group, a group interacting with a dog and a control group. ${ }^{48}$

The purpose of this study is to investigate the effects of mindfulness on self-efficacy on academic performance, pain perception and stress, and also to investigate the effect of self-efficacy on well-being outcomes when compared to placebo and control groups. It is expected that higher self-efficacy coupled with mindfulness would report less stress (part 1 and 3) and pain (part 2). Also, that a brief mindfulness intervention would increase perceived self-efficacy and moderate the relation of self-efficacy on pain reports (part 2) and perceived stress (part 3).

\section{Methods}

\section{Participants}

Ninety-two undergraduate students $(65.9 \%$ female; $\left.M_{A g e}=22.01, S D=4.84\right)$ from a Norwegian university college were invited to participate in a three-part study. Seventy of the original ninety-two participants were then exposed to an experimental condition followed by a fourweek intervention followed by post-test reporting. Some attrition of participants was present in the third part of the study as sixty-three of the initial seventy from study 2 (90\%; $\left.M_{\text {age }}=22.9 ; S D=5.42\right)$ participants responded to post-test surveys. The sample was randomized into three groups (control, sham, mindfulness) for the second and third parts of the studies.

\section{Part one - relationships of mindfulness, self-efficacy and emotions}

Participants were instructed to fill out several self-report questionnaires one month prior to the experiment:

The International Positive and Negative Affect Schedule (PANAS) is a 5-point Likert scale consisting of 20 words related to positive affect (PA) and negative affect (NA). ${ }^{50}$ Cronbach's alpha has been found to range between 0.88 and $0.90 .^{51}$

The Perceived Stress Scale (PSS) is a 14-item 5-point Likert scale that measures perceived stress in daily life. ${ }^{52}$ Cronbach's alpha ranged between 0.74 and 0.80 .

The Satisfaction with Life Scale (SWLS) is a 5-item 7-point Likert scale. ${ }^{53}$ Cronbach's alpha ranges from 0.82 to 0.87 .

The Mindfulness Attention Awareness Scale (MAAS) is a 15 -item questionnaire that aims to measure presentmoment awareness of actions, interpersonal communication, thoughts, emotions and physical states. ${ }^{54}$ The items range from 1 (agree strongly) to 5 (strongly disagree); scoring is based on the mean of the items with a high mean score indicating lower levels of mindfulness. Studies have found a Cronbach's alpha for the MAAS of $0.87 .{ }^{55}$

The Generalized self-efficacy scale (GSES) is a 10item 4-point Likert scale designed to measure perceived mastery in new and difficult situations. ${ }^{56}$ Cronbach's alpha ranged from 0.82 to 0.93 .

\section{Part two - experimental effects of intervention on pain and stress}

The second part of the study consisted of an experiment where participants were randomized into three groups; control $(\mathrm{n}=26)$, sham (placebo; $\mathrm{n}=22$ ) and mindfulness $(n=22)$ groups. Randomization occurred when students came three at a time to the psychology lab of the university and picked one of three doors. Each door led to a room that was one condition of the experiment.

Participants were then exposed to a fear induction task, ${ }^{57}$ using a Transcutaneous Electrical Nerve Stimulation (TENS/EMS) machine that induced an uncomfortable muscular stimulation in the extensor digitorum muscle. During such muscle stimulation, the hand 
and fingers contract uncontrollably, resulting in an experienced loss of bodily control. In addition to the uncomfortable sensation felt, visual feedback resulted in an increase in anxiety/fear of possible further discomfort. Participants were then asked to rate their current level of stress on a Visual Analogue Scale (VAS) (1 no pain - 10 severe pain/ as bad as it could be). ${ }^{58}$ After the first stress measurement, the participants were given shocks and the level of voltage was increased until the participant rated it as 7 in terms of unpleasantness.

The mindfulness group received a 4-mins mindfulness breathing intervention (awareness of breath). The breathing intervention was a recording from a mindfulness practitioner. This approach was based on previous findings of Shearer et al, ${ }^{48}$ who also had 5 mins interventions over 4 weeks, but while theirs was done on site, the condition in this study was done with reminders off-campus.

The sham group listened to a 4 mins long musical piece (Pachelbel - Canon in D). Music can have positive effects on anxiety in pre-operative settings but does not have any effects on physiological processes ${ }^{59}$ thus making an appropriate placebo intervention that could be measured against both the mindfulness intervention and the control situation. The control group was asked to sit quietly for four minutes. The participants were then informed that within a specific time restriction, they were required to respond to nine cognitive performance tasks, including three cognitive reflections tasks. ${ }^{60}$ They were also informed that incorrect responses may be "punishable" by a repetition of the unpleasant muscle stimulation they had previously received but with a ten percent increase in voltage. "Punishment" was decided on whether the roll of two die combined to add up to one of two numbers selected prior to the rolling of the die. This was done in order to maintain stress levels during the experiment and counteract any learned behaviors. Situational stress and self-efficacy measurements were assessed via visual analog scales before the cognitive tasks, after the fourth task and at the end of the experiment.

Part three - long term intervention effects on selfefficacy and academic performance

The third part of the study consisted of a 4-week period where participants, who were randomly assigned into one of three groups from study two (mindfulness, music, control), were instructed and reminded weekly to perform the same task under the experimental condition (mindful breathing, music) while the control group was instructed to look at a picture of balloons for 5 mins once a week. Looking at neutral pictures had no influence on emotion regulation. ${ }^{61}$ After four weeks, participants were required to retake the questionnaires from part one of the study in order to compare the effects of mindfulness and placebo (listening to music) to the control group. During Week four, participants also performed a Cognitive Psychology academic examination to see if general self-efficacy levels predicted their academic performance in examination conditions, and how the mindfulness intervention influenced this relation.

\section{Procedure}

\section{Data reduction and analysis}

All scales were centered and normalized and SPSS version 24 was used for statistical analysis. For study 1, linear regressions were calculated where well-being measures were entered as the dependent variable and mindfulness and self-efficacy were entered as independent variables. For study 2, repeated measures ANOVAs for stress and self-efficacy were calculated, and for study 3, repeated measures ANOVAs were computed for self-efficacy and satisfaction with life. Also in study 3, ANOVAs were computed to see if the groups differed on their course grade and a regression was calculated to see how post intervention self-efficacy influenced the grade.

\section{Ethical approval}

The study conformed to institutional guidelines of applying to the Norwegian Social Science Data Services (NSD) ethical guidelines for experimental studies. After initial NSD online application was filled in, formal application was not required since only non-identifiable and nonhealth-related data were used in this research. Participants gave their informed consent verbally prior to the study and were debriefed about the study's purpose after completing the data collection. Participants were informed that they could withdraw from participation at any time and without any consequences throughout and after the session.

\section{Results}

\section{Results for part I}

One month prior to the intervention phase of this study, data were collected on trait scores for all factors including trait mindfulness, generalized self-efficacy, pain tolerance and well-being behaviors. Groups were checked for differences on the mindfulness scale to check for 
initial group differences and were understood to be similar (MAAS; $F=0.55, p=0.580$ ).

Descriptives and correlations are presented in Tables 1 and 2.

A multiple regression hypothesis that mindfulness and higher self-efficacy would report less stress was calculated. Results support the hypothesis $(F(1,91)=20.38$, $p<0.001, R^{2}=0.314$, Adjusted $\left.R^{2}=0.299\right)$. Both mindfulness $(\beta=0.370, t=4.014, p<0.001)$ and self-efficacy $(\beta=$ $-0.361, t=3.313, p<0.001)$ were significant moderate predictors of stress. Self-efficacy alone accounted for $12.7 \%$ of the total variance $\left(R^{2}\right)$. Mindfulness was checked to see if it mediated the relationship between self-efficacy and stress following Baron \& Kenny's instruction, ${ }^{62}$ but this relationship was not significant $(z=0.802, p=0.146)$

\section{Results of part 2 - effect of intervention on stress}

There was a general group interaction effect on stress $\left(F(2,62)=3.374, p=0.040, \eta^{2}=0.092\right)$. Tukey's post hoc comparisons found that the mindfulness $\left(M_{\text {diff }}=1.106, p=0.020\right)$ was significantly different than the control group. The sham condition $\left(M_{\text {diff }}=0.915, p=0.058\right)$ indicated tendencies that

Table I Descriptives

\begin{tabular}{|l|l|l|l|l|}
\hline & Minimum & Maximum & M & SD \\
\hline PANAS PosAf & 1.70 & 6.40 & 3.68 & 0.70 \\
PANAS Neg Af & 0.60 & 5.00 & 2.01 & 0.65 \\
MAAS & 1.13 & 4.80 & 2.60 & 0.62 \\
SE pre & 17.0 & 57.0 & 31.35 & 5.37 \\
SE post & 20.0 & 57.0 & 32.24 & 5.57 \\
PSS pre & 5.0 & 48.0 & 22.35 & 7.93 \\
PSS post & 8.0 & 44.0 & 22.62 & 8.24 \\
PCS pre & 0.00 & 63.00 & 14.89 & 10.00 \\
PCS post & 0.00 & 38.0 & 12.10 & 8.22 \\
\hline
\end{tabular}

Abbreviations: PANAS, positive and negative affect scale; MAAS, mindfulness attention and awareness scale; SE, general self-efficacy scale; PSS, perceived stress scale; PCS, pain catastrophizing scale. differed from the control condition, but there was no significant difference between the mindfulness and sham conditions.

Further results from the experiment show that the mindfulness intervention did not have an effect on selfefficacy ( $p=0.539$ ) during the experiment. There was no significance between group differences in self-efficacy based on stress perception. Thus, intervention type did not affect perception of self-efficacy under the experimental stress-induced situation.

In part one, a median split was calculated to see how general self-efficacy influenced the experiment. Participants in the intervention groups (mindfulness, music) who rated themselves as high in self-efficacy reported tendencies toward lower levels of stress compared to the control group $(F(2,68)=2.853, p=0.064$, $\left.\eta^{2}=0.067\right)$ between high and low self-efficacy in stress effect for the different experimental groups. A Tukey's post hoc test showed that both the mindfulness group $\left(M_{\text {diff }}=0.999, p=0.043\right)$ and the sham group $\left(M_{\text {diff }}=0.970\right.$, $p=0.035)$ were significantly different from the control group. There was no significant difference between the mindfulness group and sham group $(p>0.05)$. This suggests that both mindfulness and music listening helped individuals with high self-efficacy in negating the effects of stress.

Self-efficacy together with the experimental condition was used to explain pain intensity and unpleasantness during the experiment. Only the mindfulness group predicted lower pain intensity $(F(1,22)=15.21, p=0.001$ $\beta=-0.608, R^{2}=0.369$, Adjusted $\left.R^{2}=0.345\right)$ and pain unpleasantness $\left(F(1,22)=12.154, p=0.002, \beta=-0.564, R^{2}=0.319\right.$, Adjusted $R^{2}=0.292$ ) compared to the other conditions.

\section{Results of part 3}

To test hypothesis 3 , a short mindfulness-based intervention would have positive influence on self-efficacy, pain and wellbeing (stress) in students, repeated measures ANOVAs were

Table 2 Relationship of pre-experiment questionnaires

\begin{tabular}{|l|l|l|l|l|l|l|}
\hline & $\mathbf{2}$ & $\mathbf{3}$ & $\mathbf{4}$ & $\mathbf{5}$ & $\mathbf{6}$ & $\mathbf{7}$ \\
\hline PANAS PosAf & 0.131 & -0.148 & $0.249 *$ & -0.011 & $-0.325^{* *}$ & $0.323_{* *}$ \\
PANAS Neg Af & 1 & $0.443_{* *}$ & $-0.426_{* *}$ & $0.248^{*}$ & $0.453_{* *}$ & $-0.329 * *$ \\
MAAS & & 1 & -0.174 & $0.380_{* *}$ & $0.433_{* *}$ & $-0.407^{* *}$ \\
SE & & & 1 & -0.172 & $-0.426^{* *}$ & $0.377_{* *}$ \\
PCS & & & & 1 & $0.368^{* *}$ & -0.104 \\
PSS & & & & & 1 & $-0.526^{* *}$ \\
SWLS & & & & & & 1 \\
\hline
\end{tabular}

Notes: *Correlation is significant at the 0.05 level (2-tailed). **Correlation is significant at the 0.01 level (2-tailed). 
computed on change scores. To test any differences within groups, paired sample t-tests were performed.

There were no between-group interaction effects on any of the outcome variables: self-efficacy $(F=0.16$, $p=0.891)$, stress $(F=0.46, p=0.635)$ and pain catastrophizing $(F=1.92, p=0.155)$. However, there were within group findings on several scales, self-efficacy $(F=5.30, p=0.008$, $\left.\eta^{2}=0.150\right)$ did change, but not in the direction expected. While both the control $(t=-2.75, d f=18, p=0.013$, Cohen's $d=0.94)$ and sham $(t=-1.01, d f=21, p=0.325$, Cohen's $d$ $=0.31$ ) groups showed improvements in self-efficacy scores after 4 weeks, the mindfulness group $(t=2.45$, $d f=21, p=0.023$, Cohen's $d=0.60$ ) reported worse scores after the intervention (see Figure 1).

Negative trends were highlighted for the mindfulness group on pain catastrophizing $(t=-1.69, d f=21, p=0.105)$. There was no difference between the groups in performance on the academic examination $(F=0.48, p=0.620)$, but an increase in self-efficacy, irrespective of condition, was significant in predicting grades $(F=5.05, p=0.028, \beta=2.77, t=2.25)$.

\section{Discussion}

The purpose of this study was to test if mindfulness had an effect on self-efficacy in pain perception and stress, and to test if self-efficacy had an effect on self-esteem, perceived stress and pain perception through pre/post-testing consisting of self-report questionnaires and experimentation followed by an intervention. The results from this study further demonstrate the importance of self-efficacy as a mediating factor in coping with pain and performance outcomes. The students with high self-efficacy reported

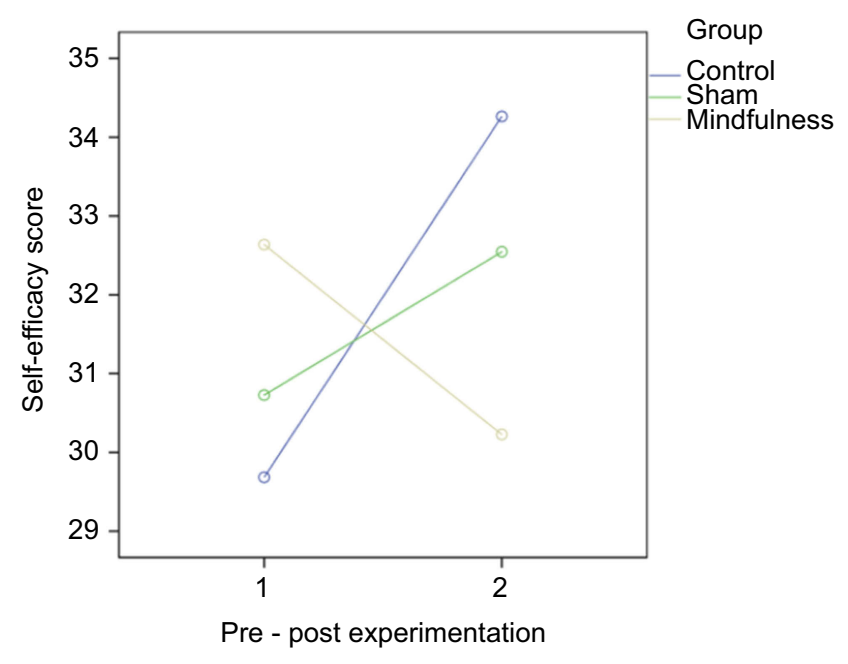

Figure I Change in self-efficacy after intervention. to have more overall positive affect and less stress than the students with low self-efficacy. These results are consistent with other studies. ${ }^{63,64}$ Levels of self-efficacy predicted positive affect, and negative affect was related to lower levels of self-efficacy. ${ }^{65}$ Results from the first part of the study support the initial hypothesis that people with high self-efficacy have higher satisfaction with life and is consistent with the findings of Azizili et al, ${ }^{29}$ that having a sense of mastery predicts well-being.

For the second part of the study, an acute mindfulness intervention had mixed results. Mindfulness had a significant influence on stress reduction, but no impact on selfefficacy. The effects of the mindfulness intervention reduced stress levels but only lasted for the initial part of the experiment (T1-T2) while there was no difference in stress levels at time 3 of the experiment between conditions. The mindfulness group however reported less pain intensity and unpleasantness. This result was not shared in the sham and control group. These results are comparable to the findings that mindfulness has good therapeutic outcomes. ${ }^{31,66}$ Both mindfulness and listening to music may be comparable activities (see Gillen et al for review on effects of music on anxiety). ${ }^{59}$ This may explain why both the mindfulness intervention and sham condition had similar results on several aspects during the experiment. Listening to music is beneficial as an intervention and may have parallels to mindful exercise. ${ }^{59}$ The results from study two might highlight the effectiveness of music as an intervention.

Hypothesis 3, in which mindfulness intervention would improve self-efficacy, could not be supported. The findings were contrary to what was expected. Mindfulness can reduce anxiety and depression but other findings show that mindfulness may also increase risk factors. ${ }^{31,67-69}$ Indeed, mindfulness increased false memory production on the Deese-Roediger-McDermott paradigm due to reduced reality monitoring. ${ }^{70}$ Also, participants who were active in mentally discarding their thoughts were better at forming non-judgmental thoughts. $^{71}$ This process is the opposite of mindful awareness where thoughts are not to be analyzed or engaged with, but instead, are given attention and coped with by not forming negative self-judgments. Several problematic factors that can arise from using mindfulness techniques have been identified but most studies on mindfulness do not include reports of adverse effects. ${ }^{42,72}$ However, these adverse effects have now been included in mindfulness-based intervention guidelines. ${ }^{43}$ 
Previous studies ${ }^{43}$ used a mixed methods design on mindfulness practitioners. It identified several domains where after effects could arise, including the cognitive domain, where problems with executive functioning (eg, memory, concentration) were identified as well as increased negative cognitive processing (mind racing and vivid imagery). Negative affective changes were also reported (increased anxiety) alongside somatic changes (loss of sleep, increased pain, gastrointestinal distress, cardiac irregularities). For motivational aspects, mindfulness had also increased anhedonia and avolition (loss of goal pursuit motivation). These results might shed light on the detrimental effects of how the mindfulness intervention had opposite effects on the experimental group than was expected. In the current study, the participants (college students) were approaching the semester examination period, which would be expected to increase stress in all students. While the control and sham the group could actively deal with negative cognitions and emotions that may have arisen during the four weeks, the experimentation group underwent a weekly mindfulness intervention where they were briefly instructed to refrain from focusing on cognitions and to focus on their breathing once a week for 4 mins. Participants may have adopted this intervention and used it actively, and thus may have experienced adverse cognitions and behaviors further supporting previous findings. ${ }^{43}$ The awareness of breath intervention could actually be counterproductive by allowing cognitions to arise without ever having learned how to be mindful in that situation. The participants were never trained in mindfulness, even though it was part of their course curriculum in cognitive psychology. While the control and sham groups could actively deal with their cognitions (ie, distraction, avoidance) as in previous studies,${ }^{71}$ the mindfulness group could have had a weekly reminder of negative cognitions that caused rumination and therefore worse outcomes. While both the control $(t=-2.75, d f=18$, $p=0.013$, Cohen's $d=0.94)$ and sham $(t=-1.01, d f=21$, $p=0.325$, Cohen's $d=0.31$ ) groups illustrated improvements in self-efficacy scores after 4 weeks, the mindfulness group had negative effects $(t=2.45, d f=21, p=0.023$, Cohen's $d=0.60$ ).

An increase in self-efficacy could predict higher grades irrespective of the experimental condition, consequently supporting our hypothesis that increased self-efficacy can predict higher academic performance and lends additional support to the similar findings that personality affects selfefficacy but that self-efficacy predicts scholastic grades. ${ }^{73}$
While the findings from the first two parts of this study further support existing research findings that increasing self-efficacy is beneficial to various positive outcomes, our results suggest that mindfulness practices may have mixed influences. Although effective in acute stress situations (part 2), the mindfulness intervention had significant detrimental effects on self-efficacy (part 3) and did not improve well-being scores, whereas the control (satisfaction with life, self-esteem pain catastrophizing) and sham (pain catastrophizing) indicated some positive outcomes. This is the opposite of the previous research demonstrating beneficial findings. ${ }^{48}$ Previous studies allowed participants to conduct their brief mindfulness exercise together in the presence of other participants, while the participants of this study were instructed to do their exercise individually may account for the difference in findings.

\section{Limitations}

Limitations include the number of participation dropouts from part 1 to part 3 (27 in total). This resulted in the exclusion of some results due to the lack of stress measurement both before and after pain induction in a few participants. During the experiment, there were some problems with apparatus in administration of the electrical stimuli. Two of the participants had to have the shock applied to the other side of the arm on the flexor carpi ulnaris muscle because the electrode could not be fastened on the extensor digitorum muscle as planned. This could potentially have had a different effect on the pain infliction. An additional limitation is the lack of the ability to control whether the students followed the reminders during the four-week intervention period. Previous studies that adopted this brief intervention were conducted in the presence of others meaning social influence have been a contributing factor, which could not have been the case in the current study. Also, there was potentially insufficient difference between the mindfulness experiences of the (sham) music group, and the mindfulness group.

\section{Conclusion}

Self-efficacy had a positive influence on cognition and satisfaction with life but the contrary was true for stress and negative affect. Self-efficacy also lowered both pain intensity and pain unpleasantness, and significantly predicted academic results. The participants in the mindfulness or sham group with pre-existing high self-efficacy had significantly lower level of stress compared to the control group. Furthermore, both mindfulness and placebo 
reduced stress compared to no intervention. Mindfulness almost indicated a significant effect as a mediator between self-efficacy in perceived stress with a single mindfulness intervention. The long-term mindfulness intervention on the other hand did not show a significant increase in selfefficacy. Results suggest that an increase in self-efficacy can have various positive outcomes and that mindfulness may increase self-efficacy short term but not necessarily in the long term. Based on these results, further research on investigating specific elements of mindfulness such as the focused breathing element in enhancing self-efficacy would be of interest. Especially, when coupled with investigating the mediating element of self-efficacy on factors such as academic performance.

\section{Disclosure}

The authors report no conflicts of interest in this work.

\section{References}

1. Loeser JD, Treede RD. The kyoto protocol of IASP basic pain terminology. Pain. 2008;137(3):473-477. doi:10.1016/j.pain.2008.04.025

2. Eccleston C, Crombez G. Pain demands attention: a cognitive-affective model of the interruptive function of pain. Psychol Bull. 1999;125(3):356-366.

3. Carpino E, Segal S, Logan D, Lebel A, Simons LE. The interplay of pain-related self-efficacy and fear on functional outcomes among youth with headache. J Pain. 2014;15(5):527-534. doi:10.1016/j. jpain.2014.01.493

4. Wright CJ, Schutte NS. The relationship between greater mindfulness and less subjective experience of chronic pain: mediating functions of pain management self-efficacy and emotional intelligence. Aust $J$ Psychol. 2014;66(3):181-186. doi:10.1111/ajpy.2014.66.issue-3

5. Bandura A. Social cognitive theory of self-regulation. Organ Behav Hum Decis Process. 1991;50:248-257. doi:10.1016/0749-5978(91)90022-L

6. Bandura A. Social cognitivetheory: an agentic perspective. Annu Rev Psychol. 2001;52:1-26. doi:10.1146/annurev.psych.52.1.1

7. Bandura A. Perceived self-efficacy in the exercise of personal agency. Psychologist. 1989;2:411-424.

8. Bandura A. Exercise of human agency through collective efficacy. Curr Dir Psychol Sci. 2000;9:75-78. doi:10.1111/1467-8721.00064

9. Bandura A. Self-efficacy: toward a unifying theory of behavioural change. Psychol Rev. 1977;84(2):191-215.

10. Gist M, Mitchell T. Self-efficacy: a theoretical analysis of its determinants and malleability. Acad Manage Rev. 1992;17(2):183-211. doi:10.5465/amr.1992.4279530

11. Luszczynska A, Scholz U, Schwarzer R. The general self-efficacy scale: multicultural validation studies. $J$ Psychol. 2005;139(5):439457. doi:10.3200/JRLP.139.5.439-457

12. Heath NL, Joly M, Carsley D. Coping self-efficacy and mindfulness in non-suicidal self-injury. Mindfulness. 2016;7(5):1132-1141. doi:10.1007/s12671-016-0555-3

13. Rokke PD, Fleming-Ficek S, Siemens NM, Hegstad HJ. Self-efficacy and choice of coping strategies for tolerating acute pain. $J$ Behav Med. 2004;27(4):343-360.

14. Luberto CM, Cotton S, McLeish AC, Mingione CJ, O'Bryan EM. Mindfulness skills and emotion regulation: the mediating role of coping self-efficacy. Mindfulness. 2014;5(4):373-380. doi:10.1007/ s12671-012-0190-6
15. Tan J, Yang W, Ma H, Yu Y. Adolescents' core self-evaluations as mediators of the effect of mindfulness on life satisfaction. Soc Behav Pers. 2016;44(7):1115-1122. doi:10.2224/sbp.2016.44.7.1115

16. Lindley LD, Borgen FH. Generalized self-efficacy, holland theme self-efficacy, and academic performance. $J$ Career Assess. 2002;10 (3):301-314. doi: $10.1177 / 10672702010003002$

17. Khodarahimi S. General self-efficacy and worry in an Iranian adolescents and youths samples. Educ Res. 2010;1(2):15-20.

18. Ross-Stewart L, Short SE. The frequency and perceived effectiveness of images used to build, maintain, and regain confidence. $J$ Appl Sport Psychol. 2009;21(S1):S34-S47. doi:10.1080/10413200802582813

19. Bishop SR, Lau M, Shapiro S, et al. Mindfulness: a proposed operational definition. Clin Psychol-Sci Pr. 2004;11(3):230-241.

20. Chambers R, Lo B, Allen N. The impact of intensive mindfulness training on attentional control, cognitive style, and affect. Cognit Ther Res. 2007;32(3):303-322. doi:10.1007/s10608-007-9119-0

21. Kabat-Zinn J. Wherever You Go, There You Are: Mindfulness Meditation in Everyday Life. New York: Hachette Books; 2009.

22. Chiesa A, Serretti A. Mindfulness-based stress reduction for stress management in healthy people: a review and meta-analysis. $J$ Altern Complement Med. 2009;15(5):593-600. doi:10.1089/acm.2008.0495

23. Zimmerman BJ, Bandura A, Martinez-Pons M. Self-motivation for academic attainment: the role of self-efficacy beliefs and personal goal setting. Am Educ Res J. 1992;29(3):663-676. doi:10.3102/ 00028312029003663

24. Hansen GR, Streltzer J. The psychology of pain. Emerg Med Clin. 2005;23(2):339-348. doi:10.1016/j.emc.2004.12.005

25. Asghari A, Nicholas M. Pain self-efficacy beliefs and pain behaviour. A prospective study. Pain. 2001;94(1):85-100.

26. Arnstein P, Caudill M, Mandle C, Norris A, Beasley R. Self-efficacy as a mediator of the relationship between pain intensity, disability and depression in chronic pain patients. Pain. 1999;80(3):483-491.

27. Meredith P, Strong J, Feeney J. Adult attachment, anxiety, and pain self-efficacy as predictors of pain intensity and disability. Pain. 2006;12(3):146-154. doi:10.1016/j.pain.2006.02.025

28. Sawatzky RG, Ratner PA, Richardson CG, Washburn C, Sudmant W, Mirwaldt P. Stress and depression in students: the mediating role of stress management self-efficacy. Nurs Res. 2012;61(1):13-21. doi:10.1097/NNR.0b013e31823b1440

29. Azizli N, Atkinson B, Baughman H, Giammarco E. Relationships between general self-efficacy, planning for the future, and life satisfaction. Pers Individ Dif. 2015;82:58-60. doi:10.1016/j.paid.2015.03.006

30. Lightsey JO, Maxwell D, Nash T, Rarey E, McKinney V. Self-control and self-efficacy for affect regulation as moderators of the negative affect-life satisfaction relationship. $J$ Cogn Psychother. 2011;25 (2):142-154. doi:10.1891/0889-8391.25.2.142

31. Kimbrough E, Magyari T, Langenberg P, Chesney M, Berman B. Mindfulness intervention for child abuse survivors. J Clin Psychol. 2010;66(1):17-33. doi:10.1002/jclp.20624

32. De Jong A, Hommes M, Brouwers A, Tomic W. Effects of mindfulness-based stress reduction course on stress, mindfulness, job selfefficacy and motivation among unemployed people. Aust $J$ Career Dev. 2013;22(2):51-62. doi:10.1177/1038416213486095

33. Caldwell K, Harrison M, Adams M, Quin R, Greeson J. Developing mindfulness in college students through movement-based courses: effects on self-regulatory self-efficacy, mood, stress, and sleep quality. $J$ Am Coll Health. 2010;58(5):433-443. doi:10.1080/ 07448480903540481

34. Yazdanimehr R, Omidi A, Sadat Z, Akbari H. The effect of mindfulness-integrated cognitive behavior therapy on depression and anxiety among pregnant women: a randomized clinical trial. J Caring Sci. 2016;5(3):195. doi:10.15171/jcs.2016.021

35. van der Riet P, Rossiter R, Kirby D, Dluzewska T, Harmon C. Piloting a stress management and mindfulness program for undergraduate nursing students: student feedback and lessons learned. Nurse Educ Today. 2015;35(1):44-49. doi:10.1016/j.nedt.2014.05.003 
36. St. Marie R, Talebkhah KS. Neurological evidence of a mind-body connection: mindfulness and pain control. Am J Psychiatry Resid J. 2018;13(4):2-5. doi:10.1176/appi.ajp-rj.2018.130401

37. Bandura A. Self-Efficacy: The Exercise of Control. New York: W.H. Freeman and Company; 1997.

38. Choi N. Self-efficacy and self-concept as predictors of college students' academic performance. Psychol Sch. 2005;42(2):197-205. doi:10.1002/(ISSN)1520-6807

39. Klassen RM, Usher EL. Self-efficacy in educational settings: recent research and emerging directions. In: Urdan TC, Karabenick SA, editors. The Decade Ahead: Theoretical Perspectives on Motivation and Achievement. Binlgley: Emerald Group Publishing Limited; 2010:1-33.

40. Zimmerman BJ. Attaining self-regulation: a social cognitive perspective. In: Vohs KD, Baumeister RF, editors. Handbook of SelfRegulation. New York: Elsevier; 2000:13-39.

41. Lustyk M, Chawla N, Nolan R, Marlatt GA. Mindfulness meditation research: issues of participant screening, safety procedures, and researcher training. Adv Mind Body Med. 2009;24(1):20-30.

42. Cebolla A, Demarzo M, Martins P, Soler J, Garcia-Campayo J. Unwanted effects: is there a negative side of meditation? A multicentre survey. PLoS One. 2017;12(9):1-11. doi:10.1371/journal. pone. 0183137

43. Lindahl JR, Fisher NE, Cooper DJ, Rosen RK, Britton WB. The varieties of contemplative experience: a mixed-methods study of meditation-related challenges in Western Buddhists. PLoS One. 2017;12(5):1-38. doi:10.1371/journal.pone.0176239

44. Taylor M, Hageman JR, Brown M. A mindfulness intervention for residents: relevance for pediatricians. Pediatr Ann. 2016;45(10): e373-e376. doi:10.3928/19382359-20160912-01

45. Sanko J, Mckay M, Rogers S. Exploring the impact of mindfulness meditation training in pre-licensure and post graduate nurses. Nurse Educ Today. 2016;45:142-147. doi:10.1016/j.nedt.2016.07.006

46. Joice S, Ramkumar T. Impact of meditation in memory of health science students. J Med Sci Clin Res. 2015;1(3):6353-6358.

47. Larson MJ, Steffen PR, Primosch M. The impact of a brief mindfulness meditation intervention on cognitive control and error-related performance monitoring. Front Hum Neurosci. 2013;7(308):1-12. doi:10.3389/fnhum.2013.00001

48. Shearer A, Hunt M, Chowdhury M, Nicol L. Effects of a brief mindfulness meditation intervention on student stress and heart rate variability. Int $J$ Stress Manag. 2016;23(2):232. doi:10.1037/a0039814

49. Andreu CI, Cosmelli D, Slagter HA, Franken IH. Effects of a brief mindfulness-meditation intervention on neural measures of response inhibition in cigarette smokers. PLoS One. 2018;13(1):1-16. doi:10.1371/journal.pone.0191661

50. Watson D, Clark LA, Tellegen A. Development and validation of brief measures of positive and negative affect: the PANAS scales. J Pers Soc Psychol. 1988;54(6):1063. doi:10.1037/0022-3514.54.6.1063

51. Crawford JR, Henry JD. The Positive and Negative Affect Schedule (PANAS): construct validity, measurement properties and normative data in a large non-clinical sample. Br J Clin Psychol. 2004;43 (3):245-265. doi:10.1348/0144665031752934

52. Cohen S, Kamarck T, Mermelstein R. A global measure of perceived stress. J Health Soc Behav. 1983;24(4):385-396. doi:10.2307/2136404

53. Diener ED, Emmons RA, Larsen RJ, Griffin S. The satisfaction with life scale. J Pers Assess. 1985;49(1):71-75. doi:10.1207/s15327752jpa4 90113

54. Carlson LE, Brown KW. Validation of the Mindful Attention Awareness Scale in a cancer population. J Psychosom Res. 2005;58 (1):29-33. doi:10.1016/j.jpsychores.2004.04.366
55. Schütze R, Rees C, Preece M, Schütze M. Low mindfulness predicts pain catastrophizing in a fear-avoidance model of chronic pain. Pain. 2010;148:120-127. doi:10.1016/j.pain.2009.10.030

56. Schwarzer R, Jerusalem M. Generalized self-efficacy scale. Meas Health Psychol. 1995;1(1):35-37.

57. Grillon C, Baas JP, Lissek S, Smith K, Milstein J. Anxious responses to predictable and unpredictable aversive events. Behav Neurosci. 2004;118(5):916-924. doi:10.1037/0735-7044.118.5.916

58. Freyd M. The graphic rating scale. J Educ Psychol. 1923;43:83-102. doi: $10.1037 / \mathrm{h} 0074329$

59. Gillen E, Biley F, Allen D. Effects of music listening on adult patients' pre-procedural state anxiety in hospital. Int J Evid Based Healthc. 2008;6(1):24-49. doi:10.1111/j.1744-1609.2007.00097.x

60. Frederick S. Cognitive reflection and decision-making. J Econ Perspect. 2005;18(4):25-42. doi:10.1257/089533005775196732

61. Johnsen SÅK, Rydstedt LW. Active use of the natural environment for emotion regulation. Eur $J$ Psychol. 2013;9(4):798-819. doi:10.5964/ejop.v9i4.633

62. Baron RM, Kenny DA. The moderator-mediator variable distinction in social psychological research: conceptual, strategic, and statistical considerations. J Pers Soc Psychol. 1986;51(6):1173-1182.

63. Arnold J, Silvester J, Cooper CL, Robertson IT, Patterson FM. Work Psychology: Understanding Human Behaviour in the Workplace. London: Pearson Education; 2005.

64. Yu Y, Peng L, Tang T, Chen L, Li M, Wang T. Effects of emotion regulation and general self-efficacy on posttraumatic growth in Chinese cancer survivors: assessing the mediating effect of positive affect. Psycho-Oncology. 2014;23(4):473-478. doi:10.1002/ pon.3434

65. Van Zundert RM, Engels RC, Kuntsche E. Contextual correlates of adolescents' self-efficacy after smoking cessation. Psychol Addict Behav. 2011;25(2):301. doi:10.1037/a0023629

66. Moss D, O’Niell B. Just another technique? Possibilities and paradoxes in working with mindfulness. Clin Psychol. 2003;31:29-33.

67. Miller JJ, Fletcher K, Kabat-Zinn J. Three-year follow-up and clinical implications of a mindfulness meditation-based stress reduction intervention in the treatment of anxiety disorders. Gen Hosp Psychiatry. 1995;17(3):192-200.

68. Segal ZV, Teasdale J. Mindfulness-Based Cognitive Therapy for Depression. New York: Guilford Publications; 2018.

69. Teasdale JD, Segal ZV, Williams JMG, Ridgeway VA, Soulsby JM, Lau MA. Prevention of relapse/recurrence in major depression by mindfulness-based cognitive therapy. J Consult Clin Psychol. 2000;68(4):615. doi:10.1037/0022-006X.68.4.615

70. Wilson BM, Mickes L, Stolarz-Fantino S, Evrard M, Fantino E. Increased false-memory susceptibility after mindfulness meditation. Psychol Sci. 2015;26(10):1567-1573. doi:10.1177/0956797615593705

71. Briñol P, Gascó M, Petty RE, Horcajo J. Treating thoughts as material objects can increase or decrease their impact on evaluation. Psychol Sci. 2013;24(1):41-47. doi:10.1177/0956797612449176

72. Lustyk MK, Chawla N, Nolan RS, Marlatt GA. Mindfulness meditation research: issues of participant screening, safety procedures, and researcher training. Adv Mind Body Med. 2017;24:20-30.

73. Di Giunta L, Alessandri G, Gerbino M, Kanacri PL, Zuffiano A, Caprara GV. The determinants of scholastic achievement: the contribution of personality traits, self-esteem, and academic self-efficacy. Learn Individ Differ. 2013;27:102-108. doi:10.1016/j.lindif.2013.07.006 


\section{Publish your work in this journal}

Psychology Research and Behavior Management is an international, peer-reviewed, open access journal focusing on the science of psychology and its application in behavior management to develop improved outcomes in the clinical, educational, sports and business arenas. Specific topics covered in the journal include: Neuroscience, memory and decision making; Behavior modification and management; Clinical applications; Business and sports performance management; Social and developmental studies; Animal studies. The manuscript management system is completely online and includes a very quick and fair peer-review system, which is all easy to use. Visit http://www. dovepress.com/testimonials.php to read real quotes from published authors. 